\title{
Death for the Coral Reefs
}

\author{
Bernard Salvat
}

Coral reefs are being destroyed world-wide by fishermen and shell collectors, by developers and above all by direct extraction for building materials. In numbers of plants and animals the coral ecosystem is one of the richest in the world, but it is also extremely fragile. The author, who is Chairman of the Coral Group set up by the IUCN Survival Service and Ecology Commissions, describes the methods used to extract coral and the disastrous effects on the reefs. As a result of the Group's recommendations French Polynesia has decided to stop coral extraction from March 1981.

The coral reefs that fringe most of the world's tropical shores cover some 600,000 square kilometres. In numbers of species they are one of the richest and most productive environments in the biosphere: Yet studies of their structure and functioning only started after the Royal Society's expedition to the Great Barrier Reef of Australia in 1930, and it is only since the second world war, and especially in the last twenty years, that much research work has been done in the three oceans.

The ecological paradox of coral reefs is due to three inherent characteristics: their high productivity, complexity, and fragility. Both the environment and the community constitute an ecological climax. But this is a tropical marine littoral climax. Over millions of years, the organisms have evolved a close interdependent relationship in comparatively stable conditions. This symbiosis between the animal and vegetable, involving a great number of reef organisms - corals and other coelenterates, bivalve molluscs and foraminifera on which the whole reef-lagoon system depends, is a superb example of association for mutual benefit. But it is also extremely fragile, for two reasons: first, because of certain very specific trophic relationships, any species injured will have an immediate repercussion on all the others; and second, the great stability of the environment through the ages has tended to produce species with a narrow habitat range (stenoecious), so that any slight change in the conditions (such as temperature, salinity, turbidity, dissolved oxygen) causes ecological disaster.

\section{Degradation and Pollution}

Coral reefs fringe the coasts of some eighty-five countries. Most of these are developing ones, and the corals are inevitably affected by the degradation and pollution caused by this very development. The threats are many, among the most important being fishing and shell collecting. Excessively large catches and over-exploitation severely reduce the natural stocks and also cause degradation, such as destruction of the coral bottom. In the search for shells coral blocks are turned over and not replaced, so that the fauna die; corals are destroyed in collecting sedentary fish species, and fishermen using explosives or chemicals do much damage. Pollution is much the same as in temperate countries: insecticides, sewage, hydrocarbons, hot water, radioactivity and, most serious of all, heavy sedimentation due to bad land management and deforestation so that soil is washed away and ends up in the lagoon. But the 
major factor in the degradation of the world's coral appears to be the direct extraction of coral, particularly in the South Pacific, where the need for building materials in developing countries is great.

This is why the International Union for Conservation of Nature and Natural Resources (IUCN) and the World Wildlife Fund supported a project to study the extraction of coral sands and its effect on the environment. The work was carried out by the Museum d'Histoire Naturelle and the Ecole Pratique des Hautes Etudes de Paris, in two regions, French Polynesia and the West Indies.

\section{Extraction}

Extracting coral sand is done by dredging the lagoon sand, either with a dredger on the shore, or with it on a barge in the lagoon itself; the former is the method most frequently used, and also the more destructive. The dredger takes the sand along the shore, where it is loaded into lorries; it is also used to build up an embankment at right angles to the shore so that it can be got out into the lagoon to get more sand. If a boat is used the dredger tips the sand into a barge from which the excess water falls back into the lagoon. What are the effects of these operations on the reefs and the lagoons, on the extraction grounds and the surroundings?

Wherever a dredger has been at work the site is of course irremediably destroyed. The excavations will be several metres deep, generally four to seven, and filled with a very fine liquid silt which is put back into suspension with the slightest movement of the water. The water is continuously turbid because the water surface is never still enough to allow the calcium carbonate particles, measuring some microns, to settle. A diver can plunge his whole arm into the 'white mud' that covers the excavation bottom. No larvae of any benthic animal, and certainly not corals, can settle on this substrate. Only a few fish are to be seen, and some medusae, but no benthic animal or algae.

The surroundings are also affected by the dispersal in the whole lagoon of the fine particles that are in continual suspension, and by the embankments. The fine particles follow the flow of the currents and form a sediment which induces abiotic and biotic modifications. But the embankments are a barrier to the currents, and parts of the lagoon, where the sedimentation of the fine particles is very important, get cut off. Large areas of reef and lagoon are affected in each extraction area with disastrous results. In the confined fringe areas, the water is not sufficiently renewed. The temperature rises during the day, sometimes to above $40^{\circ} \mathrm{C}$, and the water is continually turbid due to the ripples formed by even the lightest breeze. The sediment has smothered all the corals, which, unable to resist the effects of the silting of their bases and the continuous fall of fine particles on their polyps, are no longer able to clean themselves. The coral substrate disappears and is replaced by the soft bottom substrate, which has a characteristic stench due to the many organisms dying from lack of oxygen. Eutrophication phenomena appear. Transect studies show fewer species of corals, molluscs, crustaceans and fish in all these confined and polluted areas, several having been eliminated in the changed conditions. Conversely, the diversity and quantity of macroalgae increases, as

Opposite above: The dredger at work showing the dike built in the process of excavating Centre: The coral before and after exploitation

Below: Aerial view in Moorea, French Polynesia. The dredging dikes lie at right angles to the shore in the centre. 

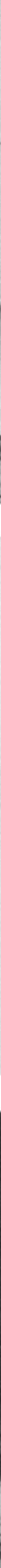
do also some species of herbivorous molluscs.

For the whole ecosystem, one of the most damaging results is the destruction of the fringe areas. These are the nursery grounds for the fry of numerous fish species which as adults live in other biota of the coral reef. The loss of these nurseries has repercussions on the fish populations of the whole reef-lagoon complex.

The cost of transporting the sand, which depends on the distance from the extraction site to the building site, is an important factor in the profitability of the operation, and results in the creation of many extraction areas. For example, on Moorea Island in French Polynesia, there are no fewer than 14 extraction sites for a perimeter of about $60 \mathrm{~km}$ - like 14 'cancers' that can spread into their surroundings. The unaesthetic aspect of these extraction areas should also be noted. Worst of all are the dredger's causeways, the dikes built by the dredger to advance into the lagoon, which survive after the exploitation has stopped. No action is taken to limit the damage they have caused and the degradation of the enclosed areas continues.

Based on the results of this study, the Coral Group has made a number of recommendations to the authorities to warn them of these ecological impacts of their destructive dredging activities. We have urged them to reduce the number of dredging zones; to exploit alternative sources of building material in land quarries; to fill up excavated zones with volcanic blocks; to confine the silt; and to destroy the extraction dikes so that the enclosed areas can be renewed, oxygenated and cleaned. As a result the French Polynesian authorities have decided to stop lagoon sand extraction as from March 1981.

This research has shown what is one of the most important causes of degradation and disturbance to coral reefs to-day. The SSC Coral Group is drawing up general recommendations on the subject, explaining, in non-scientific language for decision-makers and politicians, the effects of coral sand extractions on the environment and resources, and suggesting ways to repair damage already done to the coral ecosystem which plays such an important part in the economy of many indigenous populations.

Professor Bernard Salvat, Ecole Pratique des Hautes Etudes, 55 Rue de Buffon, 75005 Paris.

\section{Marine Reserve Needed for Dugongs and Turtles}

After a two-month survey of the Aru Islands in Indonesia for IUCN/WWF, Alain Compost describes them as an area rich in natural resources all being over-exploited and some wastefully used. People living in the eastern part of the islands kill about 1000 dugongs every year, mainly for meat for themselves, but the teeth are sold commercially, mainly to make cigarette holders. Dugongs get caught accidentally in shark nets and increasingly they are being caught this way deliberately. Every year 3000-6000 green turtles are killed for meat and two million eggs collected, all for home use, but again the first signs of commercial exploitation are there. Hawksbill turtles have decreased rapidly as a result of hunting for tortoiseshell, and adult shells are now rarely found; in 1978 over $400 \mathrm{~kg}$ of shell was exported from one area. In the Kai Islands one village of 700 people live on traditional leatherback-turtle hunting, harpooning and consuming about 100 a year. About 2000 birds of paradise are killed every year and their numbers too are decreasing; killing the males interrupts their intricate courtship. Alain Compost's immediate recommendation is that wildlife management of the area must be improved and alternative sources of food and income developed. He urges the creation of a 100,000-ha marine reserve to protect especially dugongs and turtles in the south-east corner of the islands. 